\title{
Study of the Harmonious Teacher-student Relationship in the Postgraduate Enrollment Expansion Situation
}

\author{
Shanling Han, Jinbin Li, Zhiyong Li, Qingliang Zeng \\ College of TransportationShandong University of Science and Technology, Qingdao, China \\ S.L.Han@163.com
}

\begin{abstract}
The teacher-student relationship is an important factor related to the quality of graduate education. In the situation of postgraduate enrollment expansion, teacher-student relationship has produced a series of problems. In this paper, the common problems and the causes of teacher-student relationship is discussed. It is proposed that the harmonious teacher-student relationship will be resolved only through the collaborative efforts of tutors and students in postgraduate training mechanism.

Index Terms - Postgraduate enrollment expansion, Teacherstudent relationship, Harmonious, Postgraduate training mechanism
\end{abstract}

\section{Introduction}

With the rapid development of science and technology today, science and technology innovation plays a very important role in national prosperity and revitalization of the nation. Technological innovation relies on highly qualified personnel, and higher education is an inexhaustible source of high-quality talents training. The quality of higher education will directly relate to the economic sustainable and rapid development. Since the "21st Century Education Revitalization Action Plan" put forward in 1998, the number of postgraduate students in China began to develop rapidly. The national postgraduate enrollment expansion situation of 2011-2013 is showed in table 1. It can be seen from the table, the graduate student enrollment expansion scale is increasing year by year. According to the target of "Long-term Education Reform and Development Plan (2010-2020)", the scale of postgraduate in university will reach 2 million in 2020. Such a large-scale expansion of postgraduate and the relatively limited educational resources make the graduate cultivation work produce some new problems inevitably. The teacherstudent relationship as an important factor of postgraduate education quality also encounters some new problems.

TABLE I National Postgraduate Enrollment of 2011-2013

\begin{tabular}{|c|c|c|c|}
\hline & 2011 & 2012 & 2013 \\
\hline Master & 495219 & 517200 & 539000 \\
\hline PhD & 65263 & 67216 & 69000 \\
\hline Total & 560482 & 584416 & 608000 \\
\hline
\end{tabular}

For the studies of teacher-student relationship in higher education, Li Maosheng et al [1] discussed a cooperative teacher-student relationship, it is said that it should form a relationship of mutual cooperation in teaching process between the tutor and postgraduate. The core of this new teacherstudent relationship is the cooperation between teachers and students. Zhou Qiang et al [2] put forward a new model of teacher-student relationship in the Internet age, its characteristic mainly reflected in the democracy and equality, harmony and freedom of communication and respect for the individual aspects of graduate. Ju-Ling Qiao [3] proposed that connotation illustration of teacher-student relationship, significance analysis of establishing harmonious college teacher-student relationship in the new period and suggestion of corresponding countermeasures are of great practical significance to harmonious development of education and construction of harmonious society. Graduate teacher-student relationship will create new problems at different times. This paper focuses on the problems of postgraduate teacher-student relationship and the corresponding coping strategies are given under the graduate student enrollment expansion situation.

\section{Analysis of the Current Postgraduate Teacher-student Relationship}

A. Category of Postgraduate Teacher-student Relationship

Postgraduate education is an important stage of higher personnel training, a good teacher-student relationship is conducive to the rapid growth of postgraduate and has a vital role to improve the quality of postgraduate education. After years of development, main types of postgraduate teacherstudent relationship have differentiated into four types, as shown in Fig. 1

For authoritative teacher-student relationship, the tutor has absolute authority, tutor is used in a forced behavior which characterized by order and obedience in graduate education and management. The relationship between postgraduate students and tutors are more limited in academic research, they lack necessary daily communication and proper guidance on the aspects of students' psychological and personality training [4]. For employment teacher-student relationship, the relationship between teachers and students is more of a boss and employee relationship. Graduate students participate in tutors' research projects would have been a good thing which double benefit, but for this one kind of teacher-student relationship, the projects which students participate in are most profitable projects and mostly unrelated with their projects. So there is a little help to the progress of graduate's projects.

\footnotetext{
* This work was financially supported by Postgraduate Education Innovation Program of Shandong Province (SDYY12094).
} 
The appearance of loose teacher-student relationship has a direct relation with postgraduate student enrollment expansion. The limited faculty has to deal with the increasing postgraduate scale, this leads to each graduate tutor need to be responsible for more graduate students. In addition, most tutors often play multiple roles, so they do not have sufficient time to guide their students effectively and the postgraduate management is relatively loose. This will inevitably make a negative impact on the relationship between tutors and postgraduate students. However the harmonious teacherstudent relationship is a relatively ideal type. Tutors not only guide the postgraduate study, but also he is the friend of students, the relationships of them are harmonious. It is conducive to improving the students' enthusiasm of scientific research and the academic level.

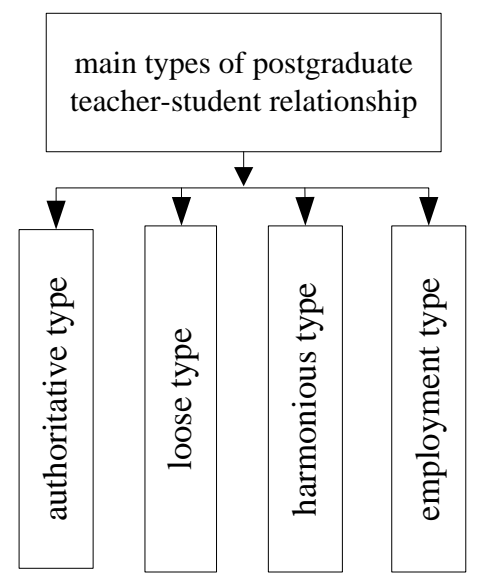

Fig. 1 four types of graduate teacher-student relationship

\section{B. The Main Problems of Postgraduate Teacher-student Relationship}

With the expansion of the postgraduate scale, it is uncommon that the news of the deteriorating relationship between postgraduate students and tutors reported frequently. Light makes students and teachers become indifferent, they do not care about each others; and in serious cases the relations between them become deteriorating, mutual hostility and even acrimony.

Considering the numerous factors and the four major teacher-student relationship types, the following three aspects are the major problems [5]:

1) The relationship between postgraduate students and tutors becomes strained, students is a hostile attitude to their tutors;

2) The relationship between students and tutors become indifferent, not essential, they do not care about each other;

3) The postgraduate students become cheap labors of their tutors to serve the tutors to obtain economic benefits.

These problems greatly affect the normal development of the teacher-student relationship and reduce the quality of postgraduate education.

\section{The causes for the problem of graduate teacher-student relationship}

The problems of postgraduate teacher-student relationship are the result of interaction of multiple factors, such as postgraduate student enrollment expansion, driven by economic interests, postgraduate training constitution unsound, etc. In short, it can be divided into internal factors and external causes between teachers and students [6].

The internal factors include that: a part of student lack of learning initiative and perseverance, without a very reasonable position and planning for their own future. Meanwhile, tutors did not distinguish their primary responsibility and trap in heavy daily work, they lack of daily communication and care to their postgraduate students [7]. The external causes include the influence of Chinese traditional teacher-student relationship, the erosion of market economy and undesirable academic atmosphere spreading [8]. At the same time, postgraduate training mechanism did not make corresponding changes or slow response to the new situation of postgraduate training.

\section{The Strategies to Improve Postgraduate Teacher- student Relationship}

Due to many aspects of the problem between postgraduate students and their tutors, a simple change is difficult to achieve satisfactory results. In the situation of postgraduate student enrolment expansion, only to establish harmonious relationship between teachers and students, this problem can be resolved fundamentally. Harmonious relationship is reflected in democracy and equality, smooth communication, understanding, trust, and optimistic and positive between teachers and students, as shown in Figure 2. However, building a harmonious teacher-student relationship is a complex process that requires all aspects participation. According to the main reasons why the problems appear between tutor and postgraduate student, the harmonious teacher-student relationship mainly is achieved through three levels of training mechanism, tutors and postgraduate students themselves to achieve.

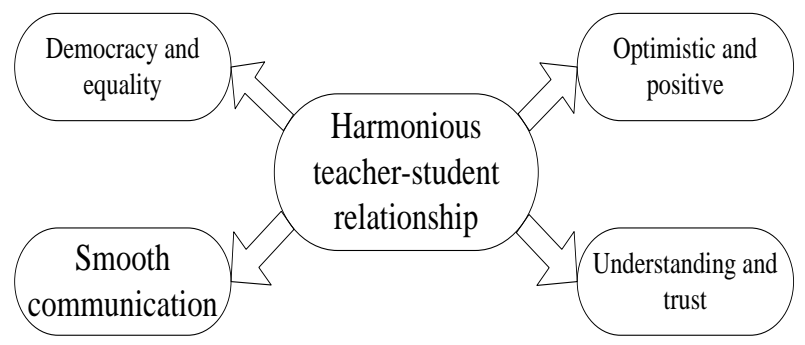

Fig. 2 Harmonious Teacher-student Relationship

\section{A. Postgraduate Training Mechanism}

Society should create a good atmosphere of academic , combat the behavior of academic fraud and academic fraudulent, eliminate unhealthy trends in society to influence academic. Same time, we should perfect the postgraduate 
student enrollment expansion system and standardize the postgraduate admission number and proportion, so that make the scale of postgraduate students at a reasonable level. Furthermore, it should improve graduate training mechanism, so that it can better adapt to the development needs of the times. At the same time, we should improve the efficient allocation of postgraduate education resources to maximize the utilization. The establishment of scientific evaluation system for students will reflect the ability of postgraduate study and research truly, so that it can stimulate students' enthusiasm innovative practices radically. Colleges and universities should provide an exchange platform and create a good academic atmosphere to maximize the ability of tutor and postgraduate research initiative. It should be improving the postgraduate tutor selection and evaluation mechanism, for example, the tutors whose responsibility is poor should be eliminated and hire excellent teachers to join the team. Then is achieved the healthy development of tutor team.

\section{B. Aspect of Postgraduate Tutors}

Tutors also plays an extremely important role in cultivate graduate work, tutors guides the direction of graduate study, it can be said that what kind of teacher would bring out what kind of student. Tutors should distinguish their primary duties, always put the graduate cultivate work in the first place. As the people who lead the way during the graduate students' study life, their impact on the growth of graduate is immeasurable. Tutor should be aware that postgraduate training is a process that comprehensive ability improves jointly, and it is not feasible to give guidance in the academic only. Tutors not only guide the academic research of postgraduate students actively, but also pay attention to improve the comprehensive ability of students. Tutor should strengthen the thoughts exchange with students, keep in touch with the thought trend of students and try hard to create a positive learning environment for students. In addition, tutors should also strengthen its own moral cultivation, to set a good example for graduate students, with their own practical actions to subtle influence of the students.. Tutor should be a good teacher in the academic research and a helpful friend in the life of postgraduate. Not only to "Give a man a fish," but also to "teach a man to fish."

\section{Aspect of Postgraduate Themselves}

The quality of graduate education ultimately depends on the students themselves. If students do not work hard, it is useless for other people do more effort. Postgraduate students as the core of the postgraduate training working, they should take positive action to create a good teacher-student relationship and a good learning environment for themselves. In the usual study life, students should learn to enhance their self-discipline, actively to learn. Meanwhile, they should enhance the individual's self-regulation ability, consciously resist the undesirable temptation of life, maintain a positive and optimistic attitude. Considering the increasing proportion of today's postgraduate student enrollment expansion and limited energy of tutors, students should be more active selflearning. Use all available learning resources around them, and actively absorb all kinds of useful knowledge to broaden their knowledge. At the same time, they should communicate with their teachers more often, so that they can mutual understand and avoid unnecessary misunderstandings between teachers and students. Only by this way, postgraduate students will provide a better environment for the smooth progress of their own research topics and the improving their comprehensive ability.

\section{Summary}

In summary, postgraduate teacher-student relationship is a problem which is advancing with the times and constantly changing. As postgraduate scale becomes larger and larger, some problems of the postgraduate teacher-student relationship have become increasingly serious. In this paper, the common problems of the relationship between tutors and postgraduate students in the situation of postgraduate student enrollment expansion are studied, and analyze their causes. On this basis, the methods to establish a harmonious teacherstudent relationship through three aspects: postgraduate training mechanism, tutors and postgraduate are proposed. It is believed that under the efforts of various aspects, the problems of postgraduate teacher-student relationship will be eased or even avoided. It will enhance the quality of postgraduate training and pro-vide a steady motive force for the country's scientific and technological innovation.

\section{References}

[1] Maosheng Li, Taifei Chen, "Cooperative graduate teacher-student relationship”, Human Resource Management, no. 6, pp. 284-286, 2010

[2] Qiang Zhou, Ting Feng, Liangwen Xia. "The exploration of graduate teacher-student relationship in the internet age". Academic Degrees \&amp; Graduate, no. 4, pp.70-73, 2011.

[3] [Qiao J-L. "Discussion on harmonious college teacher-student relationship". 19th International Conference on Industrial Engineering and Engineering Management: Engineering Management, Changsha, China, pp.1299-1306, October, 2012.

[4] Ling Ju. "Analysis of the existence of graduate teacher-student relationship". Career Horizon, no. 7, pp.72-73, 2011.

[5] Ying Guan. "Review on the study of the graduate teacher-student relationship in China”. Reform and opening-up, no.2, pp. 163-164, 2013.

[6] [Li Niu. "Investigation and countermeasures for relationship between tutors and students in graduate education". Huazhong Agricultural University, 2011.

[7] Yue-jiao Qiu, Pingping Wang. "Review on the study of the relationship between teachers and students graduate in recent five years". Humanities Expo (Theory), no. 11, pp. 81-84, 2012.

[8] Yung-chuan Chu, Wenting Chen, Shanshan Chen. "Comparative analysis and improvement measures of the relationship between students and tutors". Education and teaching research, no. 12, pp. 65-68, 2011. 